\title{
LORENZ, Sönke, MERTENS, Dieter, PRESS, Volker, Das Haus Württemberg. Ein biographisches Lexikon
}

\section{Christophe Duhamelle}

\section{OpenEdition}

\section{Journals}

Édition électronique

URL : http://journals.openedition.org/ifha/1403

DOI : 10.4000/ifha.1403

ISSN : 2198-8943

Éditeur

IFRA - Institut franco-allemand (sciences historiques et sociales)

Référence électronique

Christophe Duhamelle, « LORENZ, Sönke, MERTENS, Dieter, PRESS, Volker, Das Haus Württemberg. Ein biographisches Lexikon », Revue de l'IFHA [En ligne], Date de recension, mis en ligne le 01 janvier 1999, consulté le 22 septembre 2020. URL : http://journals.openedition.org/ifha/1403 ; DOI : https://doi.org/ 10.4000/ifha.1403

Ce document a été généré automatiquement le 22 septembre 2020.

(C)IFHA 


\title{
LORENZ, Sönke, MERTENS, Dieter, PRESS, Volker, Das Haus Württemberg. Ein biographisches Lexikon
}

\author{
Christophe Duhamelle
}

Ce dictionnaire biographique de la Maison de Wurtemberg réunit 51 auteurs et présente les rubriques selon une succession chronologique répartie par branches du lignage. Les introductions à chaque subdivision permettent de lire une véritable histoire de cette dynastie, née comme beaucoup dans la parenté des Saliens, établie dans son rang comtal sous les Staufen et dans son ancrage territorial à partir du XIIIe s. De même que les Habsbourg, les Wurtemberg sont donc des comtes d'origine, mais ils ont comme eux gravi les échelons de la hiérarchie impériale en acquérant le titre ducal en 1495. Les bouleversements napoléoniens en firent même des Electeurs en 1803 puis des rois de 1806 à 1918. Parmi la haute noblesse impériale, les Wurtemberg possèdent cependant quelques spécificités. D'une part, ils parviennent (sauf au XVe s.) à éviter les partages d'héritages qui ont affaibli tant de dynasties. Certaines possessions périphériques (le comté d'Horbourg en Alsace acheté en 1324, le comté de Montbéliard, acquis par mariage en 1397 et conservé jusqu'à la Révolution, la riche principauté d'Oels en Silésie de 1647 à 1945) permettent de satisfaire les branches cadettes. D'autre part, la position de la Diète territoriale face au duc est particulièrement forte, alors même qu'elle ne comporte pas de nobles (la noblesse locale étant immédiate et donc non soumise au prince): dès 1498, le duc Eberhard est destitué par un gouvernement issu des élites urbaines, qui retrouvent une forte position entre 1520 et 1535, lorsque les éternels concurrents Habsbourg confisquent le duché, et au XVIIIe s. quand une branche catholique vient règner sur ce pays luthérien, suscitant méfiance et conflits. Cette tradition de pouvoir partagé contribue à expliquer l'évolution relativement libérale du XIXe s.: le royaume se dote d'une constitution dès 1819 et introduit le suffrage (presque) universel en 1868, tout en demeurant distant face au modèle prussien. Ces développements généraux se reflètent dans les notices biographiques. On 
lira en particulier celle de D. MERTENS sur Eberhard V/I le Barbu (règnant de 1459 à 1496) qui fit d'un comté divisé un duché uni, de G. HAUG-MORITZ sur Carl Eugen (duc de 1737 à 1793), symbole des limites de l'absolutisme wurtembergeois, de D. LANGEWIESCHE sur Guillaume II (roi de 1891 à 1918), modèle monarchique aux antipodes de son homonyme prussien, ou encore les notices des membres actuels de la dynastie dont on mesure l'influence qu'ils ont conservée sur une région devenue, sans trop le vouloir, une République en 1918.

Christophe DUHAMELLE 